\title{
LIDERANÇA E COMUNICAÇÃO: OPINIÃO DOS ENFERMEIROS RESPONSÁVEIS PELOS SERVIÇOS DE ENFERMAGEM DE UM HOSPITAL GOVERNAMENTAL.*
}

\section{LEADERSHIP AND COMMUNICATION: OPINION OF NURSES RESPONSIBLE FOR THE NURSING SERVICES OF A GOVERNMENT HOSPITAL}

\begin{abstract}
Fabiana Corniani** Cristina Maria Galvão*** Namie Okino Sawada****

CORNIANI, F. et al. Liderança e comunicação: opinião dos enfermeiros responsáveis pelos serviços de enfermagem de um hospital governamental. Rev.Esc.Enf.USP, v.34, n.4, p. 347-53, dez. 2000.

RESUMO

No cenário da enfermagem atual, ao nosso ver, a liderança e a comunicação consistem em estratégias essenciais para a prática profissional do enfermeiro. O presente estudo teve como objetivo identificar a opinião dos enfermeiros responsáveis pelos serviços de enfermagem de um hospital governamental sobre o tema liderança e comunicação. Os dados foram obtidos em fevereiro e março de 1999 através de entrevista estruturada com doze enfermeiros. Pela análise dos dados concluímos que as opiniões relatadas, na sua grande maioria, coincide com os conceitos encontrados na literatura sobre a temática investigada. O estudo não teve como propósito esgotar o assunto, mas possibilitar subsídios para a realização de outras investigações pois, acreditamos na necessidade de investirmos esforços visando a melhor formação do enfermeiro-líder do futuro.
\end{abstract}

PALAVRAS-CHAVE: Liderança. Comunicação. Enfermagem.

\section{ABSTRACT}

In the actual nursing scenery, we believe that leadership and communication are the essential strategies for nurse's professional practice. The present study aimed at identifying the opinion of nurses responsible for the nursing services of a government hospital about the theme of leadership and communication. Data were obtained in february and march of 1999 through structured interviews with twelve nurses. Findings showed that the opinions are mostly the same as the concepts found in the literature on the theme. The study had the purpose to give elements for other investigations as we believe in the need of investments for the improvement of the formation of nurses leaders for the future.

KEYWORDS: Leadership. Communication. Nursing.

\section{INTRODUÇÃO}

O enfermeiro, dentro do contexto hospitalar, desenvolve um conjunto de ações de natureza diversa, que se articulam e se complementam entre si na consecução do trabalho em saúde. Segundo XAVIER et al (1987), as ações deste profissional podem ser consideradas de natureza assistencial, ou seja, ações direcionadas para o tratamento médico prescrito ao paciente, bem como aquelas específicas da enfermagem (por exemplo, atividades que proporcionam conforto e segurança ao cliente); de natureza administrativa, ações voltadas para a organização do trabalho da equipe de enfermagem e de natureza pedagógica, ações relativas a formação e desenvolvimento das diferentes categorias de enfermagem (educação continuada).

Nesse cenário, ao nosso ver, a liderança e a comunicação consistem em estratégias essenciais para a prática profissional do enfermeiro.

\footnotetext{
* Trabalho subvencionado pelo Conselho Nacional de Desenvolvimento Científico e Tecnológico/CNPq (Processo 520290/97-6)

*** Enfermeira. Bolsista de Iniciação Científica (1997-1999) / Projeto Integrado de Pesquisa

*** Professor Doutor da Escola de Enfermagem de Ribeirão Preto, Universidade de São Paulo. Coordenadora/Pesquisadora do Projeto Integrado de Pesquisa (crisgalv@glete.eerp.usp)

**** Professor Doutor da Escola de Enfermagem de Ribeirão Preto, Universidade de São Paulo. Pesquisadora do Projeto Integrado de Pesquisa.
} 
De acordo com TANNENBAUM et al. (1970), liderança é o exercício da influência interpessoal numa situação via processo comunicativo para que seja atingida metas determinadas.

Segundo GALVÃO (1990), o enfermeiro através da liderança tenta conciliar os objetivos da organização com os objetivos da equipe de enfermagem, buscando a melhoria da prática profissional e da assistência de enfermagem prestada.

Para TREVIZAN et al (1993), na enfermagem brasileira existe o reconhecimento da importância da liderança para o desenvolvimento do trabalho do enfermeiro nas suas diferentes áreas de atuação; entretanto, a escassez de estudos. na literatura nacional têm determinado a necessidade de investigações.

SIMÕES; FÁVERO (1998) ao analisar a liderança exercida no cotidiano pelo enfermeiro, identificaram alguns elementos de grande importância, os quais permeiam todo o processo de liderar, dentre eles, ressaltamos, a comunicação.

De acordo com STEFANELLI (1993), a "comunicação é entendida como um processo de compreender, compartilhar mensagens enviadas e recebidas, sendo que as próprias mensagens e o modo como se dá seu intercâmbio exercem influência no comportamento das pessoas nele envolvidas, a curto, médio, ou longo prazo".

Concordamos com SIMÕES (1997), ao afirmar que a enfermagem é uma área propícia para o desenvolvimento da liderança pois, o trabalho é desenvolvido por um grupo de pessoas com formação diversificada, ou seja, desde o nível elementar até o nivel superior; cabe ao enfermeiro a responsabilidade em coordenar as atividades exercidas pelos demais membros da equipe de enfermagem. Em outras palavras, compete ao enfermeiro liderar o pessoal auxiliar de enfermagem.

Frente ao exposto, entendemos que a liderança e a comunicação são recursos essenciais para o enfermeiro desenvolver a sua prática profissional. Assim, o presente estudo tem como objetivo identificar a opinião dos enfermeiros sobre liderança e comunicação no gerenciamento dos serviços de enfermagem.

\section{PROCEDIMENTO METODOLÓGICO}

A presente investigação foi realizada em um hospital geral público da cidade de Ribeirão Preto (São Paulo), consiste em uma pesquisa descritiva, na qual ${ }^{\circ}$ buscamos analisar os dados qualiquantitativamente.
O projeto de pesquisa foi submetido a apreciação do Comitê de Ética em Pesquisa do hospital investigado. Após aprovação iniciamos a coleta de dados.

Dos quatorze enfermeiros que ocupavam o cargo de diretor de serviços de enfermagem, participaram deste estudo doze, sendo que um estava no período de férias e o outro não tinha disponibilidade de horário durante o período de coleta de dados.

A coleta de dados realizou-se através de entrevistas com os enfermeiros responsáveis pelos serviços de enfermagem do hospital selecionado, nos meses de fevereiro e março de 1999.

Para a condução das entrevistas elaboramos um formulário com questões abertas referentes a temática a ser investigada (anexo A). O instrumento foi submetido a análise de três (3) especialistas (docentes da Escola de Enfermagem de Ribeirão Preto da Universidade de São Paulo) para assegurarmos a validade aparente e de conteúdo.

As entrevistas foram gravadas após autorização da divisão de enfermagem e dos entrevistados, a duração média foi de trinta minutos e a transcrição dos dados realizada pelas pesquisadoras.

Após leitura exaustiva dos relatos emitidos pelos sujeitos participantes do estudo, realizamos o confronto das suas opiniões com a literatura específica. No transcorrer da apresentação do estudo utilizamos algumas falas dos enfermeiros para ilustrar a análise realizada pelas pesquisadoras.

\section{RESULTADOS E DISCUSSÃO}

\subsection{Caracterização da Amostra}

Do total de 12 enfermeiros que participaram da pesquisa; em relação a idade, quatro $(33,3 \%)$ estão entre a faixa etária de 41 a 45 anos; três $(25 \%)$ entre 36 a 40 anos, três (25\%) entre 46 a 50 anos; um $(8,3 \%)$ na faixa etária de 30 a 35 anos e outro $(8,3 \%)$ de 51 a 55 anos. Em relação ao sexo, todos os sujeitos da amostra são do sexo feminino.

Em se tratando do tempo de conclusão da graduação (em anos), cinco enfermeiros $(41,6 \%)$ estão formados no período de 21 a 25 anos; quatro $(33,3 \%)$ entre 10 a 15 anos; dois $(16,6 \%)$ entre 16 a 20 anos, e um $(8,3 \%)$ entre 26 a 35 anos.

Em relação ao tempo de serviço no cargo, seis (50\%) estão no período de 1 a 5 anos; quatro $(33,3 \%)$ entre 6 a 10 anos, um $(8,3 \%)$ entre 1 mês a 11 meses, e um $(8,3 \%)$ entre 11 a $20 a n o s$.

De acordo com o tempo de serviço na instituição, quatro $(3.3,3 \%)$ estão trabalhando no período de 10 a 15 anos; quatro $(33,3 \%)$ entre 16 a 
20 anos; três (25\%) entre 21 a 25 anos, e um $(8,3 \%)$ entre 25 a 35 anos.

Frente ao tempo de serviço na enfermagem, cinco $(41,6 \%)$ estão na profissão no período de 21 a 25 anos; quatro $(33,3 \%)$ entre 10 a 15 anos; dois $(16,6 \%)$ entre 16 a 20 anos, e um $(8,3 \%)$ entre 31 a 35 anos.

\subsection{Descrição e Análise dos Dados}

Em relação ao conceito de liderança, os sujeitos entrevistados entendem que esta habilidade consiste na capacidade de influenciar pessoas para o alcance de objetivos, e relatam também ser a arte de coordenar o trabalho, conforme demonstram as seguintes falas:

"É a capacidade de influenciar outras pessoas para determinada ação":

"Liderança para mim é a capacidade que a pessoa tem de influenciar outras pessoas para atingir um objetivo comum".

\section{"...liderança é uma ação de coordenação":}

Esses dados coincidem com os conceitos apresentados na literatura; segundo YURA et. al (1981), liderança em enfermagem é um processo por meio do qual uma pessoa, que é o enfermeiro, influencia as ações de outros para o estabelecimento e para o alcance de objetivos comuns. De acordo com TREVIZAN et al. (1998), liderança consiste em relacionamento interpessoal, no qual o líder influencia os liderados para mudanças através da comunicação.

Para BERGAMINI (1982), o lider é "o indivíduo no grupo a quem é dada a tarefa de dirigir e coordenar tarefas relevantes nas iniciativas grupais, ou quem, na ausência do líder designado, assume a principal responsabilidade de desempenhar as funções do grupo".

Os enfermeiros investigados definem comunicação como sendo um processo que possibilita o entendimento da informação que está sendo passada, e essa poderá ser verbal, ou não-verbal. As falas a seguir apresentam esse conceito:

"..é a capacidade de expressar tudo aquilo que está dentro de você de tal maneira que todo mundo entenda...".

"É o ato de entendimento claro entre as pessoas":

"A comunicação é troca de idéias".

"Existem formas de comunicação verbal e não verbal".
Para THEWATHA; NEWPORT (1979), a comunicação é uma forma de obtermos a ação das pessoas e é entendida como o processo de emitir e compreender as informações. Os autores acrescentam ainda, que a comunicação é um meio de desenvolver a interação entre as pessoas através de uma troca de idéias, opiniões e emoções.

SIMÕES (1997) afirma que "o homem necessita aprimorar-se de mecanismos que viabilizem o seu auto-conhecimento, bem como, o "conhecer" o outro levando a um entendimento mútuo. Mecanismos esses que podem ser definidos por palavras, expressões, postura, gestos e até mesmo o silêncio, formalizando assim a comunicação".

Os enfermeiros participantes deste estudo relatam que liderança é importante na prática profissional, porque é através dela que se consegue atingir metas dentro do contexto do trabalho; além disso, ela facilita o desenvolvimento do trabalho em equipe, bem como a avaliação deste e da assistência prestada ao paciente/cliente, conforme evidenciam as falas abaixo:

"A liderança faz com que a equipe se torne uma coisa só".

"...é importante para que consigamos atingir a nossa missão, levando o grupo a ter a mesma visão":

Segundo KRON (1978), o desafio para o exercício eficaz da liderança pelo enfermeiro consiste em assegurar a qualidade da assistência prestada ao cliente, somada a qualidade do trabalho e ao respeito por cada membro da equipe como pessoa.

De acordo com SIMÕES (1997), o enfermeiro ao exercer a liderança necessita direcionar os integrantes da equipe de enfermagem através do planejamento, coordenação e avaliação do trabalho e atuar junto ao paciente e seus familiares.

Os sujeitos investigados apontam também que a liderança é um recurso que facilita a interação humana; segundo KOUZES; POSNER (1997), "os lideres devem ter competência para o relacionamento interpessoal. Você tem que ouvir, receber conselhos, abrir mão de seus argumentos e seguir alguém; você também deve desenvolver a confiança e o respeito dos outros, do contrário não conseguirá liderar".

Para os enfermeiros entrevistados a comunicação é importante na prática profissional pois, esses entendem que é através dela que ocorre o entendimento da mensagem que está sendo passada e ela também promove um bom relacionamento entre as pessoas que estão se comunicando, conforme demonstram as seguintes falas: 
"Se você não tem uma boa comunicação, você não consegue passar sua idéia ao grupo ".

"A comunicação é estritamente importante para podermos nos relacionar com o grupo":

"Se não houver uma comunicação eficiente isso só trará prejuizo ao usuário, e usuário não é só o doente, é o pessoal que está atuando (é a equipe de enfermagem, o médico, o aluno); todos que estão neste contexto":

Ao nos reportarmos aos relatos dos enfermeiros entrevistados podemos afirmar que a comunicação é um meio que o enfermeiro utiliza para influenciar a equipe de enfermagem, equipe médica, dentre outros profissionais, para o alcance de objetivos comuns.

TREVIZAN et al. (1998) afirmam que a comunicação é fundamental para o lider exercer influência, coordenar as atividades do grupo, ou seja, efetivar o processo de liderança. As autoras acrescentam que a comunicação tem como objetivo transmitir uma mensagem para uma pessoa, de tal forma que essa mensagem seja entendida corretamente.

Segundo BACHION (1994), "uma das metas primárias da comunicação, segundo a abordagem humanista, é desenvolver a compreensão entre os comunicadores". Para Barnlund apud BACHION (1994) "comunicação é uma interação que é determinada pelas necessidades de relacionamento dos comunicadores, grau de atração, percepções mútuas, onde as pessoas se auto apresentam de modo a manobrar impressões, revelando aspectos do seu eu".

Em relação a existência de dificuldades para exercer a liderança no gerenciamento do serviço de enfermagem sob a responsabilidade dos enfermeiros investigados, esses apontam a comunicação ineficaz e a diferente formação da equipe de enfermagem como sendo os principais fatores enfrentados no dia a dia do trabalho. As falas a seguir evidenciam essa abordagem:

"O serviço é muito extenso e amplo, o enfermeiro lida com todas as categorias...":

"Existe até pelo aspecto da dificuldade de comunicação".

as vezes pela comunicação não efetiva, pela falta de envolvimento das pessoas':
De acordo com MOTTA (1991), a comunicação consiste em recurso crucial do líder pois, é a maneira de aproximar-se das pessoas, trocando opiniões e idéias, aprimorando o entendimento do trabalho, avaliando o desempenho de cada membro da equipe e construindo alternativas para o futuro. $O$ autor acrescenta que é através da comunicação que o líder aprende a respeito dos liderados e os mantém informados sobre inovações, mudanças, bem como utiliza esse recurso como facilitador do trabalho em equipe.

Um enfermeiro refere dificuldades em desenvolver a habilidade de liderar por não saber como agir em determinadas situações, acredita que se tivesse um preparo melhor, saberia como agir escolhendo a melhor forma de acordo com a situação; para TREVIZAN (1993) na abordagem situacional a liderança é compreendida como um processo dinâmico, modificável de uma situação para outra, sendo o líder, os liderados e a situação as variáveis norteadoras do processo.

Segundo BENNIS (1995), a liderança pode ser aprendida, principalmente, a partir de experiências vivenciadas no cotidiano, assim, entendemos que para minimizar as dificuldades no exercício da liderança às instituições devem promover programas de educação continuada que contemplem as necessidades reais dos seus profissionais.

As dificuldades de comunicação entre enfermeiros ou entre esses profissionais e a equipe sob sua responsabilidade, de acordo com os entrevistados, ocorrem pelo fato de cada pessoa entender a mensagem de uma forma diferente, pela falta de clareza por parte de quem está transmitindo a mensagem e a falta de interesse do receptor. Podemos evidenciar esses aspectos com as seguintes falas:

'...pelas dificuldades de entendimento da comunicação, tanto em relação ao receptor, quanto ao emissor":

'...há falha na comunicação, e não atingimos a meta pretendida, porque cada um entendeu de uma forma diferente o que você queria passar":

STEFANELLI (1993) afirma que para ocorrer uma troca efetiva de mensagens é necessário que as palavras empregadas tenham o mesmo significado entre as pessoas envolvidas para tando o repertório a ser usado deve ser conhecido. Para SIMÕES; FAVERO (1998) a comunicação está presente em todas as formas de interação humana e consiste em um recurso fundamental para o líder, que deve emitir suas mensagens de tal forma que promova nos liderados o entendimento correto acarretando satisfação e melhor desenvolvimento do trabalho. 
Um enfermeiro relata que a dificuldade de comunicação existe em decorrência de obstáculos que estão presentes nas pessoas, tais como: idéias pré concebidas, preconceitos, ressentimentos e medo.

Segundo SILVA (1996), a efetividade da comunicação depende das atitudes do emissor e do receptor, bem como das crenças, valores, experiências anteriores, expectativas quanto à mensagem e o relacionamento existente entre as pessoas envolvidas no processo. Ressalta ainda, que as mensagens devem ser validadas, ou seja, o emissor e o receptor precisam verificar se tiveram o mesmo entendimento do conteúdo da mensagem.

Para o exercício da liderança na sua prática profissional, os enfermeiros entrevistados consideram importante o conhecimento científico, o relacionamento interpessoal e a competência.

MEIGHAN (1990), no seu estudo sobre as características mais importantes do lider na enfermagem sob o ponto de vista dos liderados, identificou que a experiência profissional, o conhecimento científico e a competência clínica (prática) são as características mais relevantes apontadas pelos sujeitos investigados.

Além dos aspectos comentados, os enfermeiros participantes do estudo acreditam que para exercer a liderança de forma eficaz, estes profissionais necessitam: ouvir e acatar novas idéias; proporcionar mecanismos que possibilitem o aperfeiçoamento da equipe de enfermagem; conhecer as necessidades pessoais e profissionais da equipe sob sua responsabilidade, bem como promover um relacionamento baseado na confiança. Afirmam ainda, que o líder deve reconhecer as prioridades do serviço e assumir o papel de planejador, executor e avaliador do trabalho a ser desenvolvido na unidade.

Entendemos que os aspectos apontados pelos sujeitos são fundamentais para a liderança eficaz; entretanto, salientamos aqui uma qualidade do líder que vem sendo objeto atual de investigação dos estudiosos desta temática, ou seja, a credibilidade. Por exemplo, KOUZES; POSNER (1997) afirmam que "acima de tudo, temos de ser capazes de acreditar em nossos líderes. Temos de acreditar que podemos confiar em suas palavras, que eles farão o que dizem, que sentem entusiasmo e arrebatamento com relação ao rumo que estamos seguindo, e que eles tem o conhecimento e as habilidades necessárias para liderar".

ULRICH (1996) relata que o líder do futuro deve possuir duas atribuições no exercício da liderança: credibilidade e competência. O autor afirma que o líder bem sucedido deve ter credibilidade pessoal, "líderes fidedignos possuem hábitos, valdres, traços e competências pessoais que geram confiança e compromisso naqueles que dirigem"; além disso, o líder necessita ser capaz de desenvolver competência administrativa. "Essa competência provém de líderes que podem adaptar, estruturar, implementar e melhorar processos organizacionais para atingir metas empresariais".

Em relação as sugestões que os enfermeiros investigados consideram importante para minimizar as dificuldades de comunicação entre esses profissionais ou entre eles e a equipe de enfermagem, destacamos: a necessidade de saber ouvir e falar, a comunicação clara e objetiva, conforme apresentam as seguintes falas:

"É necessário ouvir atentamente, sem intervenção e prestar atenção no outro":

"É importante saber ouvir e falar":

"Primeiro eu acho que a pessoa deve saber ouvir, mais do que falar, depois fazer uma sintese do que ouviu e ver se entendeu exatamente o que você disse".

"Primeiro a comunicação deverá ser clara e objetiva e explicando o porque...".

"Que cada um pare para ouvir e olhe para quem fala, que seja claro...":

Para BACHION (1994) o enfermeiro deve ser capaz de expressar-se verbalmente de forma clara e objetiva empregando as palavras adequadas e ao falar com as pessoas verificar o nivel de compreensão.

Um dos enfermeiros entrevistados acredita ser necessário para uma boa comunicação, vivenciar as situações, tentar aprender com os erros, definir o canal a ser utilizado, falar a mesma linguagem, e existir entendimento e seriedade entre as pessoas envolvidas.

Outro acredita que é fundamental reforçar sempre os objetivos comuns, incentivar o respeito com a equipe, envolver as pessoas que estão se comunicando e partilhar informações e idéias para melhorar a tomada de decisão.

Ao nos reportarmos aos relatos emanados dos sujeitos podemos afirmar que os aspectos abordados por estes são extremamente importantes para a efetividade do processo de comunicação.

ROBBINS (1997) destaca as principais barreiras que acarretam menor efetividade no processo de comunicação, a saber: filtragem -quando é comunicado apenas uma parte do que o emissor/ receptor sabem, pensam ou sentem; percepção seletiva -as pessoas comunicam-se baseadas em suas necessidades, motivação, experiências anteriores, dentre outras características pessoais, elas projetam seus interesses e expectativas ao decodificarem a mensagem; defensiva -quando as pessoas sentem-se ameaçadas ocorre redução da sua capacidade de 
compreensão mútua; linguagem- as palavras significam diferente para pessoas diferentes, sendo a idade, a formação e a cultura algumas das variáveis que influenciam a linguagem que as pessoas utilizam.

\section{CONSIDERAÇÕES FINAIS}

A temática pesquisada é ampla e complexa, entendemos que a sua importância para a prática profissional do enfermeiro fica clara ao visualizarmos a liderança e a comunicação como estratégias que possibilitam a melhoria da qualidade da assistência prestada ao paciente/cliente e o desenvolvimento do potencial da equipe de enfermagem.

Frente aos resultados evidenciados podemos afirmar que os enfermeiros entrevistados possuem opiniões que coincidem com os conceitos encontrados na literatura sobre a temática investigada. Salientamos a importância da situação levantada pois, acreditamos que somente o enfermeiro poderá tornar-se um agente de mudanças no contexto da enfermagem, a partir do momento que este profissional compreender e utilizar as diferentes ferramentas que poderão auxiliá-lo no seu dia a dia de trabalho, neste estudo destacamos apenas duas, ou seja, a liderança e a comunicação.

O presente estudo não teve o propósito de esgotar o assunto, pelo contrário acreditamos que existe a necessidade de investirmos esforços em investigações nos mais diversos contextos de atuação da enfermagem e de propormos ações que possam ser implementadas com vistas a formação do enfermeiro-líder do futuro.

\section{REFERÊNCIAS BIBLIOGRÁFICAS}

BACHION,M.M. Comunicação interpessoal: ensino de algumas habilidades desejadas. 1994. 141p. Tese (Doutorado) - Escola de Enfermagem de Ribeirão Preto, Universidade de São Paulo.

BENNIS, W. A invenção de uma vida: reflexões sobre liderança e mudanças. Rio de Janeiro, Campus, 1995.

BERGAMINI, C.W. Psicologia aplicada à administração de empresa. 3. ed. São Paulo, Atlas, 1992.

GALVÃO, C.M. Liderança do enfermeiro de centro cirúrgico. Ribeirão Preto, 1990. 69 p. Dissertação (Mestrado) - Escola de Enfermagem de Ribeirão Preto, Universidade de São Paulo.

KOUZES,J.AM.; POSNER, B.Z. O desafio da liderança. 2.ed. Rio de Janeiro, Campus, 1997.
KRON,T. Manual de enfermagem. 4. ed. Rio de Janeiro, Interamericana, 1978.

MEIGHAN,M.M. The most important characteristics of nursing leaders. Nurs. Adm.Q., v.15, n.1, p. 63-69, 1990.

MOTTA, P.R. Gestão Contemporânea: a ciência e a arte de ser dirigente. 2 ed. Rio de Janeiro, Record, 1991.

ROBBINS,S. P. Organizational Behavior: concepts, controverssies, applications. 8. ed. New Jersey, Prentice Hall, 1997.

SILVA,M.J.P. Comunicação tem remédio: a comunicação nas relações interpessoais em saúde. 2. ed. São Paulo, Gente, 1996.

SIMÕES.A.A.L. 0 ser lider no cotidiano do profissional enfermeiro. Ribeirão Preto, 1997. 126p. Dissertação (Mestrado) - Escola de Enfermagem de Ribeirão Preto, Universidade de São Paulo.

SIMÕES,A.A.L; FÁVERO,N. Influência da comunicação na liderança do enfermeiro. In: CARVALHO,E.C. (org.) Comunicação em Enfermagem: relatos de pesquisas do $6^{\circ}$ Simpósio Brasileiro de Comunicação em Enfermagem. Ribeirão Preto, Fundação Instituto de Enfermagem de Ribeirão Preto, 1998. cap.15, p.69-73.

STEFANELli,M.C. Comunicação com o paciente-teoria e ensino. São Paulo, Robe, 1993.

TANNENBAUM, R. et al. Liderança e organização: uma abordagem à ciência do comportamento. Trad. por Auriphebo B. Simões. São Paulo, Atlas, 1970.

TREVIZAN,M.A Liderança do enfermeiro: o ideal e o real no contexto hospitalar. São Paulo, Sarvier, 1993.

TREVIZAN, M. A. et al O esperado e o praticado pelo enfermeiro em relação à liderança no ambiente hospitalar: visão do atendente de enfermagem. Adm. Saúde, v. 17, n.1, p.31-4, 1993.

TREVIZAN,M.A. et al. Liderança e comunicação no cenário da gestão em enfermagem. Rev. Latino-am. Enf., v.6, n.5, p.7782, 1998.

TREWATHA, R. L.; NEWPORT, M. G. Administração: funções e comportamento. Trad. por Auriphebo B. Simões. São Paulo, Saraiva, 1979.

ULRICH,D. Credibilidade X Competência. In: HESSELBEIN,F.; GOLDSMITH,M; BECKHARD,R. O lider do futuro: visões, estratégias e práticas para uma nova era. São Paulo, Futura, 1996. cap.21, p.213-222.

XAVIER, I.M. et al. Subsídios para a conceituação da assistência de enfermagem rumo à Reforma Sanitária. Rev. Bras. Enf.; v. 40, n. 2/3, p.177-80, 1987.

YURA,H. et al. Nursing leadership: theory and process. 2. ed. New York, Appleon Century - Crofts, 1981. 